\title{
Research on the practical teaching system for Computer Network Technique based on skill competitions and its applications
}

\author{
She Minghong ${ }^{1, a}$, Yang Hongbing ${ }^{2, b}$ and Tang Jiyong ${ }^{3, a}$ \\ ${ }^{1}$ Computer College, Chongqing College of Electronic Engineering; Chongqing Shapingba,China , \\ 401331 ,mh_she@126.com \\ ${ }^{2}$ Sichuan Minzu College; Sichuan Kangding 626001,China

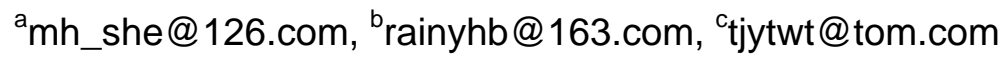

\begin{abstract}
Keywords: skill competition; innovation; Computer Network Technique; practical teaching; research Abstract. The teaching of Computer Network Technique is critical to improvement of students' computer skills. In the new era, the educational system has been under reform, which puts forward a higher requirement of the teaching practices of Computer Network Technique. Under the traditional computer teaching mode, teaching methods lack diversity and teaching effects are insignificant. The teaching of Computer Network Technique based on skill competition can efficiently improve students' practical abilities. Concerning the issue, this paper first analyzes problems existing in the teaching of Computer Network Technique, and then explores teaching practices of Computer Network Technique based on skill competitions.
\end{abstract}

\section{Introduction}

Applications of skill competitions to teaching practices are an innovation of traditional teaching methods. In the skill competition platform, competitions can be used to promote teaching and facilitate learning. The teaching concept can also be applied to Computer Network Technique. Through formulation of specific teaching objectives, teachers can choose proper teaching content for Computer Network Technique.

\section{Teaching status of Computer Network Technique}

In order to promote teaching of Computer Network Technique, many vocational schools have worked with foreign enterprises, including Cisco, Digital China, Ruijie, Guangzhou Vcom and so on, to introduce the network technical system of the latter to teaching practices of Computer Network Technique. In this way, the teaching of Computer Network Technique can be reformed to coincide with social teaching reform and improve teaching effects.

Enterprises' technical requirements of graduates show that the teaching of Computer Network Technique should progress along with the times. Graduates with strong teamwork spirit, innovational abilities and psychological qualities are more marketable. In response to such requirements, the teaching practices of Computer Network Technique should be reformed. During the practical reform process, skill competitions can provide a clear direction for the deepened reform of Computer Network Technique, and boost school-enterprise cooperation [1].

With the constant development of technology, the teaching of Computer Network Technique should make full use of teaching facilities. However, the current classroom teaching of Computer Network Technique still follows the traditional teaching mode, which cannot fundamentally improve students' enthusiasm in learning Computer Science. Under the traditional teaching mode, teachers think that a large number of exercises can help students improve their academic performance. However, students gradually lose their initiative to learn and fail to draw inferences about other cases from one instance.

Students majoring in Computer Network Technique cannot efficiently apply their knowledge into practices. This directly suggests problems with the teaching content design. Even students think that what they learn from teachers are inapplicable in life. To secondary vocational school students, 
computer teaching just serves exams. The established concept of students also reflects the ills with the teaching content of the current computer teaching [2].

\section{Strategies for innovative teaching practices for Computer Network Technique}

Launch of a network technique application competition in a vocational school.

1. Competition objectives. A "Computer Network Technique Application Skill Competition” is held in a vocational school. Objectives of the network technique application competition includes promoting the teaching development of Computer Network Technique, boosting school-enterprise cooperation, realizing combination of learning with working, intensifying the skill teaching of Computer Network Technique, bringing up technical talents and conducting a spot test of skills of students majoring in Computer Network Technique.

2. Competition content and venue. Competition content: Students majoring in Computer Network Technique compete with each other in the form of groups. According to the given task, different groups are expected to finish corresponding network design, and ensure that the design can meet the customization requirements. In terms of the competition hardware environment, every group is equipped with a set of computer. In terms of the competition software environment, there is Windows Server 2003, Packet Tracer 5.3 and other software of a higher version [3].

3. Grading methods. Competition groups are required to finish certain amount of tasks within limited time. After finishing the basic requirements, they can get basic points. When the total points of two or several teams are the same, teams are ranked in terms of whether they can finish their tasks. Table 1 and Table 2 below are competition rating standards:

Table 1 Test Module 1

\begin{tabular}{|c|c|c|c|}
\hline Competition content & Point distribution & Grading standard & Point deduction standard \\
\hline Basic configuration & 10 points & $\begin{array}{l}\text { Basic security configuration for } \\
\text { the host computer ( } 1-5 \text { points) }\end{array}$ & $\begin{array}{l}\text { No host name configuration ( } 3 \text { points off) } \\
\text { and lack of standard host name ( } 2 \text { points } \\
\text { off) }\end{array}$ \\
\hline Network planning & 21 points & $\begin{array}{l}\text { Network interface selection (1-3 } \\
\text { points) } \\
\text { Twisted-pair selection (1-2 points) } \\
\text { IP address (1-16 points) }\end{array}$ & $\begin{array}{l}\text { Incorrect network interface selection ( } 3 \\
\text { points off) } \\
\text { Incorrect twisted-pair selection ( } 2 \text { points } \\
\text { off) } \\
\text { Incorrect IP address planning (15 points } \\
\text { off) }\end{array}$ \\
\hline $\begin{array}{l}\text { Interchanger } \\
\text { configuration }\end{array}$ & 29 points & $\begin{array}{l}\text { VTP configuration (1-12 points) } \\
\text { VLAN configuration (1-12 points) } \\
\text { VLAN route configuration (1-5 } \\
\text { points) }\end{array}$ & $\begin{array}{l}\text { Lack of VTP configuration ( } 8 \text { points off) } \\
\text { Incorrect VLAN configuration (10 points } \\
\text { off) }\end{array}$ \\
\hline Route configuration & 10 points & $\begin{array}{l}\text { Dynamic route configuration (1-10 } \\
\text { points) }\end{array}$ & $\begin{array}{l}\text { Incorrect dynamic route configuration ( } 8 \\
\text { points off) } \\
\text { Incorrect dynamic route security } \\
\text { configuration ( } 2 \text { points off) }\end{array}$ \\
\hline Total & 70 points & & \\
\hline
\end{tabular}

Table 2 Test Module 2

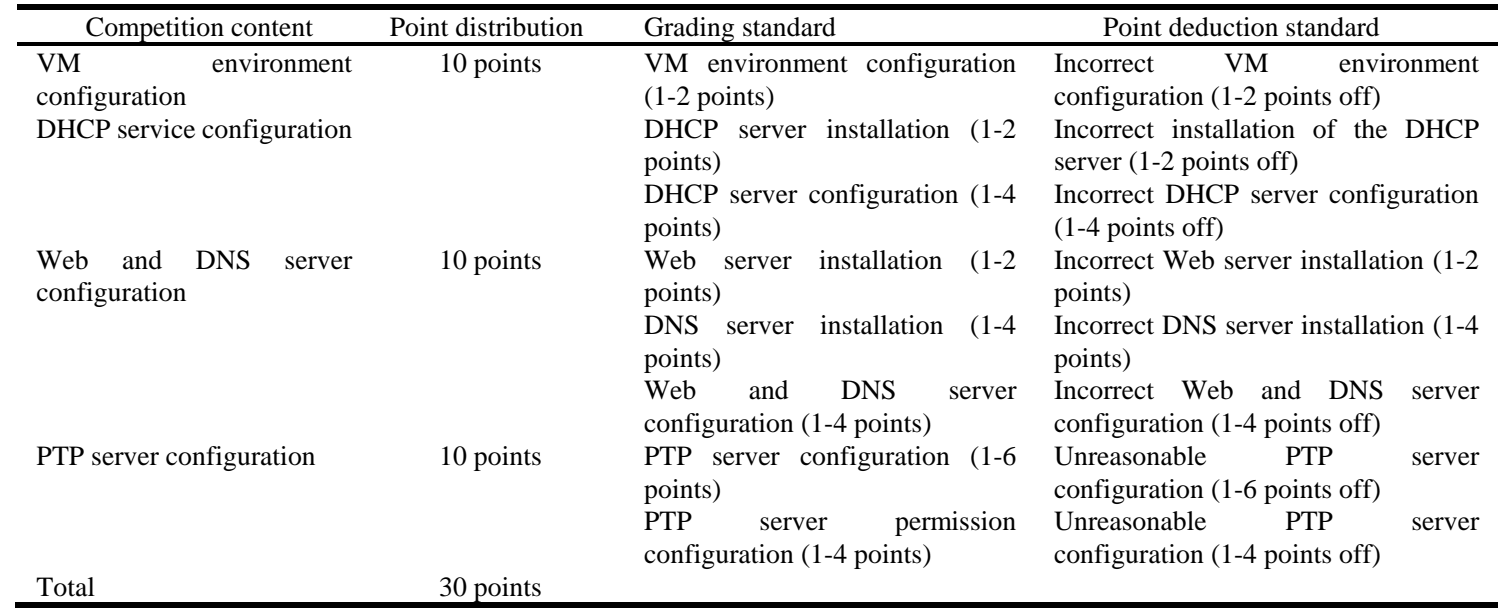


Teaching design and competition topic selection. During the teaching process of Computer Network Technique, the teaching content can be combined with skill competitions so as to invigorate the teaching atmosphere. Different skill competitions can guide students to employ different knowledge and build different knowledge models. During competitions, students can improve their ability through website establishment, inserting a table into a webpage and so on. In terms of the competition topic selection, novel and simple ones can be chosen so as to attract students' attention. Innovation of practical teaching can transform teaching content difficult to understand in classroom into competition content, which can stimulate students' self-study potential and improve their teaching effect [4].

Clarification of competition-based practical teaching. When students are interested into the competition topic, they will take the initiative to search relevant knowledge and review relevant knowledge points after class. Compared with the traditional teaching mode based on the book knowledge, the teaching mode can get twofold results with half the effort. After key teaching points are clarified, teachers need to guide students about how to apply the acquired knowledge points into practices. In this way, students can flexibly apply their knowledge to solve practical problems.

Several issues to address during the competition-based teaching process include how to prompt students to apply theoretical knowledge into practices, how to guide students to distribute labor and cooperate with each other in the competition preparation round and how to lead students to innovate after finishing a specific project [5].

\section{Conclusions}

To sum up, this paper analyzes the practical teaching status of Computer Network Technique and existing problems. The author comes to the conclusion that the curriculum teaching of Computer Network Technique should catch up with times. In response to requirements of enterprises, students should develop strong teamwork spirit, innovational ability and psychological qualities. To the end, the practical teaching of Computer Network Technique should be reformed. The innovational network technique teaching practices based on skill competitions can efficiently improve practical skills of students.

\section{Acknowledgements}

This work was supported by Chongqing College of Electronic Engineering Education Education Reform Project Project Name: Research and Practice relying on skills competition Innovation Network Technology Practice Teaching System Project Number: 201401, Chongqing Municipal Higher Education Teaching Reform of key projects, Project Name: Research and Construction of Electronic Information to Professional Practice Teaching Evaluation System Project Number: 142059, and Chongqing Education Science and planning issues, project name: Impact Factors and Countermeasures Electronic Information of Higher Vocational Students' professional identity. Project number: 2014-GX-137.

\section{References:}

[1] WU Yingjian. Exploration of innovational talent training in higher vocational colleges[D]. Fudan University, 2013.

[2] SHAO Wenting. Research into undergraduate faculty team training for Network Engineering[D]. Fujian Normal University, 2014.

[3] TONG Xiaoling. On the innovational entrepreneurship education system of research-type universities[D]. Wuhan University of Technology, 2012. 
[4] CAO Yang. On the entrepreneurship education in higher vocational colleges against the backdrop of economic development[D]. Northeast Normal University, 2014.

[5] NUE Chunli. Research into the status of the practical teaching system in institutions of higher education in Guangxi and optimization strategies[D]. Guangxi Normal University, 2011. 